\title{
O ESPAÇO E O TEMPO NA GEOGRAFIA DAS RELAÇÕES HUMANAS NA LITERATURA DE LIMA BARRETO
}

Laurides Lescano Antunes de

Aquino $^{1}$ ( Unigranrio)

Idemburgo Pereira Frazão

Félix $^{2}$ (Unigranrio)

(...) a cidade é, por excelência, o espaço da criação, da destruição e da conservação [...] é possível realizar uma leitura da cidade, pois ela se assemelha a um arquivo. Ela guarda, em todo seu processo de transformação, a memória viva de seu passado. Tem sempre o passado como presente. (O Rio de Todos os Brasis- Carlos Lessa)

\section{RESUMO}

O presente artigo objetiva criar um diálogo entre a Geografia e as demais áreas das Ciências Humanas com ênfase na problemática da opressão e da exclusão social, vividas pelo escritor Afonso Henriques de Lima Barreto. Sua literatura, como forma de expressão nos permite refletir sobre as desigualdades e injustiças sociais por ele vividas, num período histórico muito conturbado política e socialmente, na cidade do Rio de Janeiro, por ocasião da forte influência da cultura europeia. No que tange ao espaço geográfico, a cidade virou cenário para os estudos de Lima Barreto, que significativamente lutou pela perpetuação da cultura brasileira através de suas fortes críticas ao regime vigente. Neste contexto, o espaço, o tempo e a subjetividade nos abrem um leque de oportunidades para compreendermos melhor as relações humanas através de crenças, dos valores individuais e de sentimentos que nos enriquecem por intermédio de experiências. Lima Barreto incorporou à alma da cidade do Rio de Janeiro os seus personagens, embutindo-lhes o sentimento de identificação e a noção de pertencimento ao lugar. $\mathrm{O}$ escritor fez uma leitura das ruas de sua cidade flanando pelos bares e cafés, onde se reuniam de operários a intelectuais, descobrindo neles partes da história e da cultura brasileiras.

Palavras-chave: $\quad$ Espaço, Literatura, Lima Barreto

\footnotetext{
${ }^{1}$ Graduada em Geografia pela Unisuam. Mestra em Humanidades Cultura e Artes pela Unigranrio

2 Doutor em Literatura Comparada pela UFRJ. Professor do PPG em Humanidades, Cultura e Artes da Unigranrio. Bolsista de Produtividade FUNADESP
} 


\section{SEMINÁRIO DE PESQUISA EM CIÊNCIAS HUMANAS - SEPECH \\ Humanidades, Estado e desafios didático-científicos \\ Londrina, 27 a 29 de julho de 2016}

\section{INTRODUÇ̃̃O}

O presente artigo tem como intuito abordar o espaço urbano da cidade do Rio de Janeiro através da literatura de Afonso Henriques de Lima Barreto, escritor de estilos e gêneros literários diversos. Escreveu textos para jornais, crônicas, contos, romances, sátiras. Suas fortes, eloquentes e ácidas críticas revelaram em sua obra, as desigualdades sociais marcantes no período da República Velha, relacionando a realidade social às imposições da Administração Pública do Prefeito Pereira Passos, cujo espaço geográfico serviu de mecanismo de opressão tanto para o escritor como para grande parte da população carioca.

Ao conceito de espaço agregam-se além dos tradicionais, novas perspectivas geográficas visando à compreensão do papel do homem, as suas reações individuais e como seu comportamento pode alterar ou modelar o espaço. Surge nos anos 70 a escola do pensamento humanístico. Essa vertente humanística foi enriquecida pelas contribuições do geógrafo chinês, radicado nos Estados Unidos, Yi- Fu Tuan através de um novo repensar da Geografia, alinhado às demais áreas humanas, ele nos apresentou um novo modo de compreender o conceito de espaço e lugar que excederam os conceitos antigos, se estendendo às linhas literárias. De acordo com Tuan (1983), "o que começa como espaço indiferenciado transforma-se em lugar à medida que $o$ conhecemos melhor e o dotamos de valor." (p.6)

É importante ressaltar que o espaço, além de se reproduzir pelas instâncias sociais, também resulta da interação do homem com o lugar de produção e de consumo, é o próprio cotidiano do homem, o lugar em habita, trabalha e se diverte, de acordo com suas necessidades e práticas.

Uma das possibilidades que a vertente humanística nos proporcionou foi a de reconhecer o comportamento de uma sociedade através da formação dos espaços sociais focalizando não só a produção do homem como também suas emoções, suas lutas, as conquistas alcançadas, conflitos e derrotas. Partindo do pressuposto de que o espaço influencia as ações humanas e pode se tornar um forte mecanismo de opressão e exclusão social, é que podemos destacar algumas contribuições a respeito da interligação do espaço geográfico da cidade do Rio de Janeiro com a cidade do Rio de Janeiro de Lima Barreto. Enquanto o foco da geografia humanística se volta para a busca de melhorias do meio ambiente integrando o homem em sua Natureza, ele por sua vez, cria condições de utilizá-la transformando-a, na criação de novos espaços.

Cabe ressaltar que geograficamente, espaço e lugar apresentam conceitos diferenciados. Santos (1978) afirma que o espaço geográfico é também o cotidiano, muda o enfoque da abordagem de espaço geográfico para lugares, cujas formas são dotadas de conteúdo e de significado voltados para ação humana e seu entorno. Segundo João Baptista Ferreira de Mello (1990)

o lugar, recortado afetivamente, onde as pessoas se sentem seguras e à vontade, emerge nas experiências cotidianas, nos locais de moradia, trabalho, compras, lazer e encontros. (MELLO, 1990, p.32)

Tuan (2013) fundamenta a relação da Geografia Humanística com os espaços e lugares, onde espaço se torna um conjunto complexo de ideias com pessoas de diferentes culturas. De acordo com alguns geógrafos, a geografia humanística 


\section{SEMINÁRIO DE PESQUISA EM CIÊNCIAS HUMANAS - SEPECH \\ Humanidades, Estado e desafios didático-científicos \\ Londrina, 27 a 29 de julho de 2016}

aproximou o mundo das artes ao mundo da geografia, oferecendo-lhe um toque de magia na literatura ao trazer para o campo real, valiosas ferramentas que traduziram a verdadeira essência a respeito das ideias sobre lugar e espaço. Coube à Geografia Humanística permitir ao homem materializar seu sentimento através das imagens que são criadas no universo abstrato do escritor.

É importante também ressaltar que no âmbito das ciências humanas a literatura de Afonso Henriques de Lima Barreto nos reportou a um caminho de análise e interpretação de determinados aspectos sociopolíticos e econômicos com bases críticas do comportamento da elite carioca dos séculos XIX e XX. Esse entrelaçamento de Lima Barreto (literatura) e a cidade do Rio de Janeiro (espaço geográfico) coloca a cidade como cenário principal dessa realidade destacando o espaço ocupado e suas representatividades sociais. A cidade do Rio de Janeiro do escritor Lima Barreto por ocasião da administração do Prefeito Pereira Passos passou pelo processo de remodelação com obras de reformas sanitárias e urbanas, além de vários focos de doenças, perdeu seu aspecto colonial para se tornar uma verdadeira capital. Muitas demolições ocorreram, velhas construções foram colocadas abaixo, dando lugar a várias avenidas e uma delas a conhecida Avenida Central, arquitetada nos moldes europeus, da Champs Elysées e outras que ligariam o subúrbio ao centro.

O espaço se define como um conjunto de formas representativas de relações sociais do passado e do presente e por uma estrutura representada por relações sociais que se manifestam através de processos e funções (SANTOS, 1978, p.122)

Devido à falta de planejamento urbano, a insatisfação do povo carioca se agravou, no momento em que as demolições no centro do Rio começaram, deslocando a população para os cortiços e favelas classificadas de insalubres e impróprias para moradia.

As obras da cidade, além do embelezamento, também foram alvo de críticas e motivo de descontentamento para muitos, entre eles o de escritor Lima Barreto. $\mathrm{O}$ escritor fez uma leitura da cidade do Rio de Janeiro, abordando a temática urbanística e sanitária, traduzindo, num rico conteúdo imaginário a realidade de seu espaço geográfico. Lima Barreto propôs a analisar e a viver as particularidades de sua cidade percorrendo ruas e consequentemente recolhendo personagens por onde passava. $\mathrm{O}$ espaço geográfico tornou-se, portanto um elemento fundamental na literatura do escritor, devido à sua íntima relação com o meio. Partindo dessa concepção que o homem e a cidade se interagem, ficou fácil compreender a influência que a geografia humanista exerceu nas relações sócio-espaciais.

\section{A CIDADE SOB O OLHAR DA LITERATURA}

De acordo com o pensamento geográfico, as necessidades do homem em buscar um espaço para se abrigar e garantir seu sustento, favoreceram o surgimento das cidades acarretando as transformações sócio-espaciais, econômicas, culturais e políticas, permitindo mais tarde que se desenvolvessem os primeiros núcleos urbanos. Angela Maria Thereza Lopes (2012) em O Rio de Lima Barreto: modernização e modernidade, 


\section{SEMINÁRIO DE PESQUISA EM CIÊNCIAS HUMANAS - SEPECH \\ Humanidades, Estado e desafios didático-científicos \\ Londrina, 27 a 29 de julho de 2016}

define: "A cidade é o locus onde se amplia a capacidade humana de evolução e invenção; é também geratriz de diversidade, segregação e violência". (LOPES, 2012, p.34)

A cidade em questão cresce em proporção ao fluxo migratório, à força de trabalho e à demanda por mão-de-obra. Esse fluxo, além de geográfico, apresenta também um caráter histórico, cujo binômio homem-cultura se constitui através deste fluxo. Por conseguinte o papel do espaço em relação à cidade se consolida quando a geografia alinhada à outras áreas de estudos nos fornece um potencial apropriado para a compreensão das transformações pelas quais o homem sofre em decorrências dessas mudanças, principalmente, quando elas não são atendem seus interesses.

Robert Moses Pechman (1997) afirma que "as cidades são conhecidas desde os confins da história, mas que o fenômeno urbano é inédito na experiência humana". A cidade do Rio de Janeiro de Lima Barreto se faz presente em nosso imaginário, por intermédio de suas crônicas e romances, fazendo de sua cidade, o cenário principal de suas investigações literárias, cujos personagens simbolizavam a insatisfação decorrente da organização inadequada do espaço, das mudanças culturais pela influência europeia, onde a elite econômica e governo passaram a importar os hábitos e os valores europeus. Estes hábitos incentivaram ao governo a uma pequena parcela da população a adotarem medidas cada vez mais excludentes. Os pontos de cafés, os salões de baile, o vestuário, o consumo de produtos importados e outros tantos, foram algumas das fortes razões que levaram Lima Barreto, a escrever suas ácidas críticas à questão da reforma urbana de Pereira Passos.

Lima Barreto incorporou a paisagem da cidade, conseguindo de tal forma traçar um panorama intelectual e até mesmo pitoresco, flanando pelas ruas do Rio de Janeiro, em busca de personificar personagens para seus romances, criando tipos eloquentes que discutiam política, artes, e os mais variados assuntos da época. Como enfatiza Antônio Edmilson Martins Rodrigues:

A "rua" é o símbolo do viver moderno, por onde transitam os diversos tipos sociais, onde esses tipos ganham expressão e sentido, se constroem e crescem, e onde, finalmente, discutem a sua existência. (RODRIGUES, 2000, p. 107)

Em muitos pontos, a cidade do Rio de Janeiro, foi atingida. Não só nas reformas urbanas e sociais como a questão religiosa também foi motivo de intolerância por parte da elite. As religiões afro-brasileiras foram condenadas, bem como o violão, instrumento alvo de proibição na época, pois a elite carioca o associava à malandragem e à boemia. Alguns escritores e intelectuais se juntaram a Lima Barreto reproduzindo suas insatisfações através de crônicas, gênero literário muito usada no período em questão.

Lima Barreto comparou os atos das autoridades brasileiras aos dos mandachuvas de Bruzundangas, personagens fictícios, do país Bruzundangas, uma de suas produções literárias. Assim como a vontade do prefeito em realizar a reforma urbana de modo radical e desrespeitosa, o personagem fictício do conto acima, o Visconde Pancome, herói de Bruzundangas também desconhecia os desejos de seu povo. 


\section{SEMINÁRIO DE PESQUISA EM CIÊNCIAS HUMANAS - SEPECH \\ Humanidades, Estado e desafios didático-científicos \\ Londrina, 27 a 29 de julho de 2016}

Convenceu-o que deveria modificar radicalmente o aspecto da capital. Era preciso, mas devia ser feito lentamente. Ele não quis assim e eis a Bruzundanga, tomando dinheiro emprestado, para pôr as velhas casas de sua capital abaixo. De uma hora para outra, a antiga cidade desapareceu e outra surgiu como se fosse obtida por uma mutação de teatro. Havia mesmo na cousa muita de cenografia. (BARRETO, s/d, p.45)

O fato de o governo negar e condenar a cultura popular e de expulsar do centro da cidade os menos favorecidos, abriu espaço para que o escritor reproduzisse em sua literatura, a escrita em alguns folhetins utilizando o deboche e o cinismo em suas críticas. Uma crônica de Lima Barreto que salienta a parceria do governo com algumas empresas multinacionais é $A$ Estação (1921), que destaca um fator que sinalizava o advento do bonde elétrico na cidade do Rio de Janeiro. Ao mesmo tempo em que ele se preocupava com a vinda da tecnologia observava que a população ainda não estava preparada para absorver tais progressos. A visão de João Baptista Ferreira de Mello (1990, p. 102) nos remete ao modo de como o homem vivencia suas experiências e como as percebe, "Assim o lugar é recortado emocionalmente nas experiências cotidianas".

Lima Barreto ao pontuar suas crônicas e romances teve como base dois fatores sociais importantes: a segregação racial e social, enfatizando os espaços nos quais se sedimentam os que foram afastados da formação do processo histórico o qual a cidade foi envolvida. Ele acreditava que a missão da literatura era unir os homens, uma vez ter sofrido tão perceptivelmente, com esta segregação, a ponto de não ter obtido o reconhecimento intelectual e da elite. Conforme enfatiza Joachin Azevedo Neto em Uma Outra Face da Belle Époque Carioca:

O espaço urbano, enquanto lócus (sic) múltiplo,é um terreno em aberto para muitas abordagens historiográficas. Interessa aqui encarar a cidade enquanto lugar fragmentado e territorializado através das práticas sócioculturais. Neste sentido é que a cidade se torna múltipla e pode ser estudada através dos textos literários que a representam, pois estes imprimem no visível e no invisível as lembranças, experiências e memórias que circulam pelas suas praças, bairros e ruas. (NETO, 2011, p.19)

A cidade do Rio de Janeiro, enquanto espaço geográfico passou a viver a ideologia da modernidade, abandonando aos poucos seus velhos hábitos, à proporção que seus casarões iam abaixo, a paisagem foi se modificando recebendo outros contornos que de certa forma mascarou a realidade de seus moradores.

Para Regis de Morais (1983) "este homem tão especial tinha na vida dois principais amores: a literatura e a cidade do Rio de Janeiro." A intensidade dos personagens vivificou os espaços geográficos. O escritor deixa claro em sua obra o quanto a segregação espacial afastou aqueles postos à margem das decisões da sociedade capitalista da época. Não se sabe ao certo o ano em que a Belle Époque teria entrado no cenário carioca, todavia pode-se identificar o período em que a geografia da cidade do Rio de Janeiro começou a sofrer com as influências das reformas urbanísticas e sociais. Uma grande parte da população que aspirava por essas reformas também 


\section{SEMINÁRIO DE PESQUISA EM CIÊNCIAS HUMANAS - SEPECH \\ Humanidades, Estado e desafios didático-científicos \\ Londrina, 27 a 29 de julho de 2016}

desejava a formação de uma nova identidade para poder se alimentar de novos valores importados e conflitantes. Mediante tal posicionamento, podemos justificar determinadas implicações no que tange à geografia do comportamento ao abordar que cada indivíduo apresenta uma escala diferente de percepção e avaliação em relação à formação de seu espaço social e geográfico. A relação do escritor Lima Barreto com seus personagens ia além de seus escritos, não se infundindo somente por suas histórias bem como priorizando em sua literatura, os menos afortunados social, moral e culturalmente. Seu sentido de pertencimento se expandia à medida que as tradições brasileiras deixavam de ser cultivadas e que o regime político passou a ignorar como prioritário, o cunho social.

Enquanto a maior parte das crônicas do escritor sobre o centro do Rio de Janeiro enfocava o caráter autoritário que as reformas urbanas possuíam e criticava a futilidade das elites que desfilavam nesse cenário a lá "Buenos Aires de Tostão", suas impressões sobre as fisionomias dos subúrbios possuíam uma riqueza de detalhes impressionantes. Se Lima foi um cronista apaixonado pela sua cidade, inclusive pela área nobre, com suas praias e jardins projetados, preservou nas suas descrições sobre as áreas destinadas ao morar dos populares cariocas uma espécie de afetividade que demonstrava o que de mais humano poderia se encontrar nesses lugares. (NETO, 2011, p. 66)

Cabe ressaltar que no em final do século XIX a comparação da cidade do Rio de Janeiro à cidade de Buenos Aires era uma prática constante. A imprensa criticava a parte da higiene da cidade, a falta de melhoramentos. A cidade de Buenos Aires, no final do século XIX, foi remodelada usando como paradigma a cidade de Paris, modernizando-se justamente no período da influência europeia. Buenos Aires se diferenciou das demais cidades pelo confronto existe entre seu crescimento econômico e a pobreza, por ser considerada uma metrópole ao estilo da Belle Époque europeia criou condições para se tornar cidade modelo de modernização.

\section{A GEOGRAFIA DO ESCRITOR E O REFLEXO DA REFORMA URBANA}

A reforma urbana de Pereira Passos atuou com objetivo principal de embelezar a área central e a zona sul da cidade. Esse processo de remodelação trouxe um crescimento acelerado da economia, multiplicaram-se as indústrias e a ascensão do capital financeiro. A população sentiu-se atraída pelo crescimento da cidade que procuraram se instalar próximo a seus locais de trabalho, muitos chegavam de áreas rurais à procura de trabalho. A população pobre cresceu desproporcionalmente em relação ao número de moradias. Com a demolição dos cortiços, os operários não tiveram muitas alternativas a não ser residirem próximo ao trabalho e como não tinham escolha, os morros que circundavam o centro da cidade passaram a ser melhor forma de habitação para eles. Isso explica evidentemente o quanto a administração de Pereira Passos se tornou contraditória. Segundo Maurício de Abreu em 2013:

Finalmente, o período Passos também se constitui em exemplo de como as contradições do espaço, ao serem resolvidas, muitas vezes geram 


\section{SEMINÁRIO DE PESQUISA EM CIÊNCIAS HUMANAS - SEPECH \\ Humanidades, Estado e desafios didático-científicos \\ Londrina, 27 a 29 de julho de 2016}

novas contradições para o momento de organização social que surge. [...] Concluindo, o período Passos, verdadeiro período Haussman à la carioca, representa, par ao Rio de Janeiro, a superação efetiva da forma e das contradições da cidade colonial-escravista, e o início de sua transformação em espaço adequado às exigências do Modo de Produção Capitalista. (ABREU, 2013, p. 66-67)

Algumas cenas descritivas figuram como natureza viva onde se encontram escritor e seu espaço existindo uma verdadeira correspondência com a realidade de quem a escreve, num determinado momento Lima Barreto se envaidece com a grandeza da imagem imaginária, porém tem os pés no chão ao compará-las à paisagem europeia. Assim numa manhã de 07 de janeiro de 1905 declarava em formato de crônica, sua paixão pela cidade do Rio de Janeiro.

Beatriz Resende em Lima Barreto e o Rio de Janeiro em Fragmentos (1993, p.106) afirma que o escritor assume a "função social de intelectual interlocutor entre o povo e o público" por meio de seu descontentamento com o modelo de reforma imposto pelos dirigentes, aproveita as tensões sociais para satirizar a República e compor sua literatura. A tecnologia abraça a cidade do Rio de Janeiro no século XIX e com isso muda sua geografia, acelerando a modernização do porto do Rio, nos novos meios de transportes pela instauração dos bondes elétricos e automóveis. Considerando o espaço como produção social, a cidade foi se transformando, alguns bairros com Saúde, Santo Cristo e Gamboa permaneceram próximos ao porto, entretanto Gávea, Laranjeiras, Vila Isabel e outros perderam suas características de bairros industriais, adquirindo novas funções, constituindo novos espaços e originando novas moradias consideradas como impróprias e insalubres. Reforçando que a relação espaço-sociedade se sustenta na força produtiva, na organização do trabalho, na estrutura econômica, na interação e ações dos grupos sociais não se pode compreender essa totalidade sem as bases interdisciplinares que valorizam o tributo teórico e prático na transformação de antigos conceitos geográficos.

A relação existente entre o poeta e a cidade se estreita. Ele dialoga com a estética pré-modernista, utilizando as crônicas como abordagens críticas, procurando garantir à literatura, o papel de sua verdadeira identidade nacional. A literatura se une à geografia, a partir do momento em que o poeta enfatiza seu espaço romanesco às suas experiências dando sentido a eles. $\mathrm{O}$ homem e a cidade se interagem, tornando compreensível a influência da geografia humanística nas relações sócio-espaciais.

O processo de modernização embelezou a cidade do Rio de Janeiro, sua geografia natural foi modificada, dando lugar ao estilo arquitetônico francês. Os boulavares ${ }^{3}$ e jardins passaram a fazer parte da paisagem carioca em substituição às ruas estreitas e aos velhos sobrados, considerados insalubres e inadequados às moradias. A ligação da Avenida Beira-Mar ao Porto da cidade, iniciando a ocupação da orla marítima, assim como a construção da Praça Mauá, da Praça Floriano, o Passeio Público que originou o primeiro jardim público da cidade, a Praça Tiradentes, um manguezal, a Praça da República antigo esgoto colonial, a Praça XV construída sobre aterros. Essa remodelação causou uma devassa na cidade, as demolições dos casarões e cortiços deram lugar às avenidas citadas acima.

\footnotetext{
${ }^{3}$ Palavra de origem francesa que significa avenidas ou ruas largas.
} 


\section{SEMINÁRIO DE PESQUISA EM CIÊNCIAS HUMANAS - SEPECH \\ Humanidades, Estado e desafios didático-científicos \\ Londrina, 27 a 29 de julho de 2016}

A cirurgia urbana de Pereira Passos é extensa. Rasga a avenida Passos e a Treze de Maio. O morro do Senado, desmontado, dá origem em seu centro à atual Praça da Cruz Vermelha.[...] Estruturou a abertura da avenida Osvaldo Cruz. Reorganizou o Largo da Cancela, antigo ponto de partida da Estrada Real de Santa Cruz. (LESSA, 2005,p.202)

Lima Barreto ao delinear o espaço da cidade objetivou defender a memória da cultura brasileira buscando na literatura bases para combater as imposições e as desigualdades instaladas no período de transição do Império para República que representava para o escritor, o símbolo da modernidade. Mesmo com o poder nas mãos, o prefeito Pereira Passos enfrentava a oposição do Conselho Municipal, deliberando em favor de seus próprios interesses, dos especuladores e dos grandes construtores. A disparidade entre a cidade e os bairros se agrava por consequência da segregação sócioespacial afastando a população operária do centro urbano. Lima Barreto viveu essa segregação, até mesmo pela sua condição de ser negro, suburbano, pobre e alcoólatra. Não sendo reconhecido em vida como escritor, tampouco obteve a aprovação para entrar para Academia Brasileira de Letras, por ser considerado pela elite acadêmica, um escritor de menor peso que os demais escritores brancos. Assim na crônica Leitura de Jornais (1921) o escritor destaca a falta de interesse dos administradores em relação às necessidades vitais da população da cidade do Rio de Janeiro que se orientavam pela estética urbana europeia.

O interesse pelas obras de saneamento da região portuária foi o incremento para a expansão das relações comerciais visando à arrecadação de rendas devido à grande movimentação de mercadorias. De acordo com Carlos Lessa (2005) a modernização do Rio foi um projeto sem consulta à sociedade. Conforme Idemburgo Frazão (2014):

A cidade - com sua história, seu cotidiano, sua beleza, suas mazelas pode ser entendida, em termos de temática e de argumento, como a espinha dorsal de obras importantes de Lima Barreto, como Clara dos Anjos, Recordação do Escrivão Isaías Caminha, Vida e Morte de MJ Gonzaga de Sá, e várias outras, incluindo aí seus contos e crônicas. (FRAZÃO, 2014, p.11)

\section{CONCLUSÃO}

$\mathrm{O}$ que se propôs com o artigo "O espaço e o tempo na geografia das relações humanas na literatura de Lima Barreto" foi uma reflexão sobre a relação do escritor carioca pelo viés da literatura, sob o olhar das diferenças espaciais e sociais, no período da Belle Époque. O diálogo entre o espaço geográfico e a obra de Lima nos permitiu compreender a interação com o outro, a condição de coletividade e a forma como somos vistos pelo outro. A literatura abriu portas para percebemos o quanto a segregação social, racial e espacial causou profundas marcas de ressentimento e indignação tanto no escritor como na maioria da população da cidade do Rio de Janeiro. A cidade como capital adaptou-se às mudanças e se rendeu à nova burguesia, cujo objetivo era não aceitar a velha identidade nacional e a negar qualquer elemento de identidade cultural que se remetesse à sociedade tradicional. Grande parte da população pagou um preço muito caro devido à nova transformação urbanística e social. Escritor e personagens se 


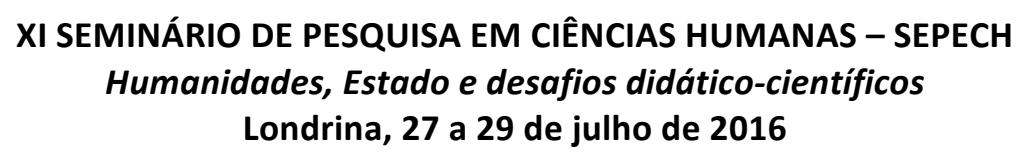

mesclaram com o mesmo propósito, o de buscar sua identidade e o sentido de pertencimento ao lugar da maneira direta como eles se viram em relação ao espaço do qual não foram inseridos. Sua maneira ácida e irônica de escrever só foi aceita após sua morte, não tendo o prazer de ser reconhecido ainda em vida pela academia literária. Seus personagens saíram das páginas dos livros e da ficção validando o espaço geográfico e o literário. Dessa forma, o sentido de pertencimento e não pertencimento relativo aos espaços e lugares das narrativas de Lima Barreto, criou um laço imaginário entre o leitor, o escritor e seus personagens.

Importante destacar a oportunidade de inserir no presente texto as contribuições teóricas das demais Áreas das Ciências Humanas aproximando a Geografia e a Literatura à essência do homem - escritor Lima Barreto, recuperando o caráter geográfico existente em sua obra. Por essa proposta mergulhamos no mundo imaginário do escritor com a intensidade de viver seus personagens, na luta pelas intervenções impostas pelas mudanças históricas e geográficas ocorridas na transição do XIX para o XX.

\section{REFERÊNCIAS}

ABREU, Mauricio de Almeida. A evolução urbana do Rio de Janeiro: $4^{\mathrm{a}}$ ed. Rio de Janeiro: IPP, 2013.

BARRETO, Lima. Toda crônica. Organizado por Beatriz Resende e Raquel Valença. vol 1 e 2. Rio de Janeiro: Agir, 2004.

. Os bruzundangas. São Paulo: Ática, 2001.

FÉLIX, Idemburgo Pereira Frazão. A cidade e seu escritor: a relação da biografia e da literatura de Lima Barreto com a Belle Époque. Revista Magistro. vol.9. nº 1, 2014.

LESSA, Carlos. O Rio de todos os brasis. Rio de Janeiro: Record, 2005.

LOPES, Angela Maria Thereza. O Rio de Lima Barreto: Modernização e Modernidade. Curitiba: CRV, 2012.

MELLO, João Baptista Ferreira de. Geografia humanística: A perspectiva de experiência vivida e uma crítica radical ao positivismo. Revista Brasileira de Geografia v.52. nº 4, Rio de Janeiro: IBGE, out/dez, 1990.

MORAIS, Regis de. Lima Barreto. São Paulo: Brasiliense, 1983.

NETO, Joachin Azevedo. Uma outra face da belle époque carioca. Rio de Janeiro: Multifoco, 2011.

PECHMAN, Robert Moses. Pedra e discurso: Cidade, História e Literatura. Revista Semear 3 . Instituto Camões. PUC - Rio de Janeiro, 1997. 


\section{SEMINÁRIO DE PESQUISA EM CIÊNCIAS HUMANAS - SEPECH \\ Humanidades, Estado e desafios didático-científicos \\ Londrina, 27 a 29 de julho de 2016}

RESENDE, Beatriz. Lima Barreto e o Rio de Janeiro em fragmentos. Rio de Janeiro: Editora da UFRJ, 1993.

RODRIGUES, Antonio Edmilson Martins. João do Rio. A cidade e o poeta. Rio de Janeiro: FGV, 2000.

TUAN, Yi- Fu. Espaço e lugar: a perspectiva da experiência. Trad. Lívia de Oliveira. Londrina: Eduel. 2013. 